\title{
Investigating the influence of friction conditions on finite element simulation of microscale machining with the presence of built-up edge
}

\author{
Samad Nadimi Bavil Oliaei ${ }^{1}$ - Yiğit Karpat $^{1,2}$
}

Received: 23 June 2016 / Accepted: 4 September 2016 / Published online: 10 September 2016

(C) Springer-Verlag London 2016

\begin{abstract}
In micromachining, the uncut chip thickness is less than the cutting tool edge radius, which results in a large negative effective rake angle. Depending on the material properties, this large negative rake angle promotes built-up edge (BUE) formation. A stable BUE acts like a cutting edge and affects the mechanics of the process. The size of the BUE increases with increasing uncut chip thickness and cutting speed. It also creates a positive rake angle, but it decreases the clearance angle of the tool. A method of including BUE formation in finite element simulations is to use sticking friction conditions at the tip of the tool. However, this approach is shown to be insufficient to simulate BUE formation in microscale machining. Therefore, the cutting edge is modified with the experimental BUE size in the finite element simulations based on experimental measurements. The influence of friction models between BUE and the work material has been investigated, and the study identifies friction coefficients that yield good agreements with experimental results. The finite element model is shown to be capable of simulating process forces and chip shapes for uncut chip thickness values larger than minimum uncut chip thickness.
\end{abstract}

Keywords Cutting $\cdot$ Micromachining $\cdot$ Built-up edge $\cdot$ Titanium alloy $\cdot$ Finite element simulation

Yiğit Karpat

ykarpat@bilkent.edu.tr

1 Department of Mechanical Engineering, Micro System Design and Manufacturing Center, Bilkent University, Bilkent, Ankara, Turkey

2 Department of Industrial Engineering, Bilkent University, Bilkent, Ankara, Turkey

\section{Introduction}

Microscale machining has become a staple technology for the fabrication of microscale components, which are used in high value-added products in many different industries [1-3]. Developing predictive techniques to improve the quality of micro parts has emerged as an important research area. In micromachining, the interaction between the cutting edge geometry and the work material significantly affects the outcome of the process [4]. Mechanistic modeling approach is commonly used in modeling the micromachining process [5-9]. Mechanistic modeling requires some experimental work to be performed in order to map the combined influences of work material, friction conditions, tool material, and geometry to some cutting coefficients. It is crucial to develop physicsbased machining models capable of predicting process outputs without conducting time-consuming experiments [10]. Finite element simulation of machining processes depends strongly on material constitutive model parameters and friction coefficients between the tool and the work material. In recent studies, 2D finite element simulations are employed to predict machining forces, which are then used to calculate cutting force coefficients of mechanistic modeling [11, 12]. This approach allows simulating 3D micro milling process forces and predicting part quality [13].

An important observation in microscale machining is the formation of built-up edge (BUE) on the cutting tool. It is commonly observed when machining ductile metals like steel, aluminum, and titanium alloys. In micromachining, the uncut chip thickness is usually less than the cutting tool edge radius and cutting speed is low which create conditions promoting BUE formation. If BUE is not stable, that is, if it is continually breaking and reforming during machining, it is known to be detrimental to tool life. However, a stable BUE may be beneficial for tool life. Tool wear and the influence of BUE while 
Fig. 1 a SEM image of the cutting edge. b $2 \mathrm{D}$ edge profile for $t_{u}=1 \mu \mathrm{m}$ a
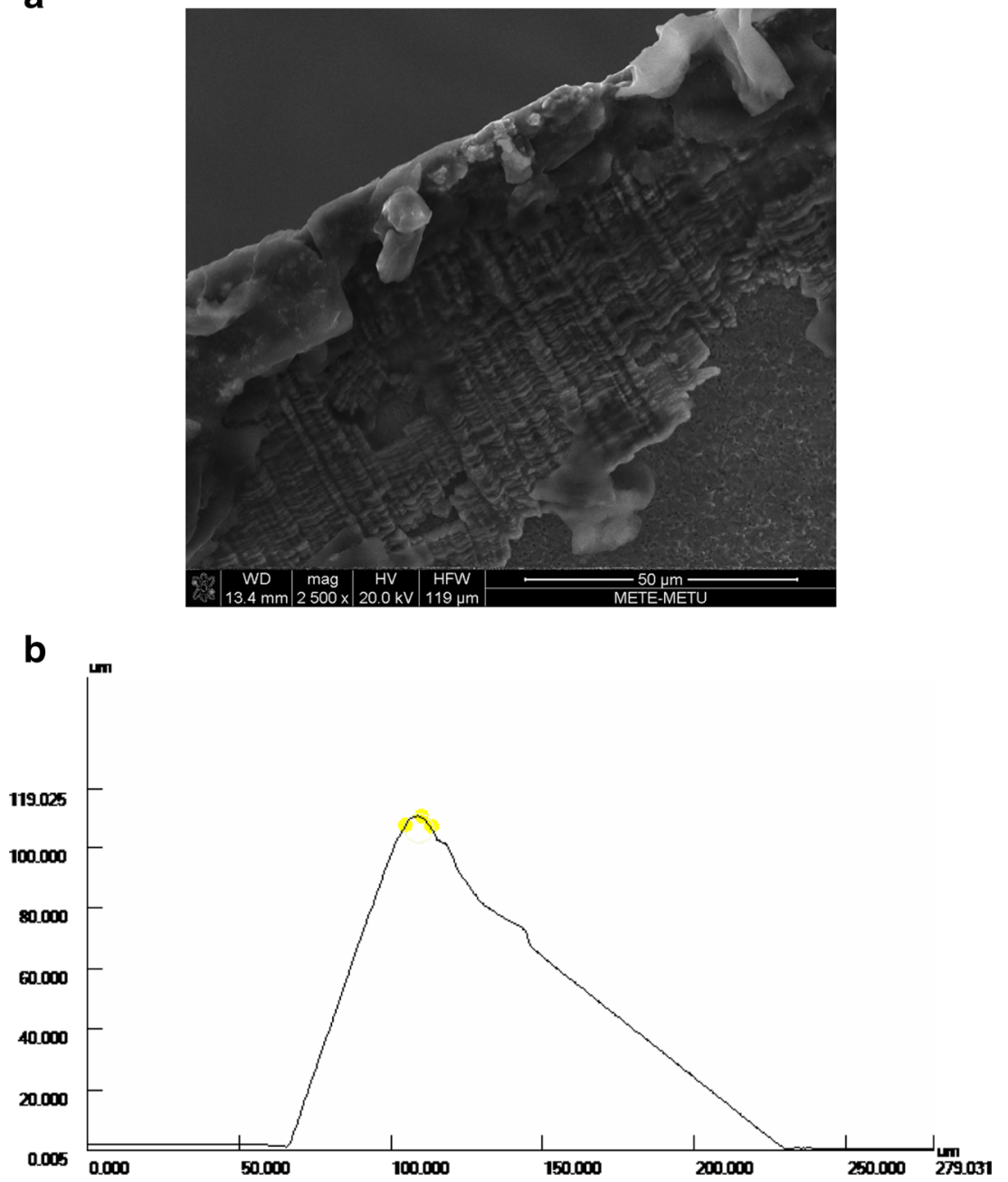

machining titanium alloys were investigated by Hartung and Kramer [14], who have shown that the formation of an adhesion layer helps to prevent sliding at the tool chip interface and hence improves tool life. Recently, Kümmel et al. [15, 16] used this idea to improve tool life by creating dimples on the tool surface, which increases BUE adhesion on the cutting tool. Oliaei and Karpat [17] studied microscale machining of titanium alloy via micro turning tests and reported the protective effect to stable BUE on the tool. A closely related issue to BUE is the built-up layer (BUL), which is defined as the material accumulation on the rake face of the tool $[18,19]$. It has been shown that during dry titanium machining, a BUL first forms on the rake face, which then gives rise to BUE formation at the tool tip [14]. In the literature, the influence of stable BUE has been considered in analytical models of machining such as Waldorf et al. [20], Fang and Dewhurst [21], and Karpat [22]. The number of studies that simulate BUE in finite element based models is limited [23]. Recently, Childs [24] developed a damage model and integrated it into a finite element simulation software to predict BUE during macroscale machining of steel, and micromachining was considered as a special case. The formation of BUE is a time-dependent phenomenon; therefore, it is a challenge to capture it in finite element models. In addition, BUE also affects the friction conditions at the tool-chip and toolworkpiece interfaces, where the cutting tool material is no longer directly in contact with the chip and the machined surface. Atlati et al. [25] investigated the influence of BUE on friction conditions while macroscale machining of aluminum alloy by introducing a time-dependent friction concept to simulate BUE formation with a finite element simulation. They assumed that changing friction conditions affect the velocity distribution in front of the cutting tool and low velocity region in front of the tool simulates BUE formation.

This study considers finite element simulation of microscale orthogonal machining with the presence of BUE. Its approach modifies cutting edge geometry based on experimental BUE observations. The focus is on friction models and their influence on the process outputs. Results of a recent study [17] conducted on BUE formation in micromachining are first briefly discussed, and secondly, the influence of the friction model on finite element simulation is investigated. 


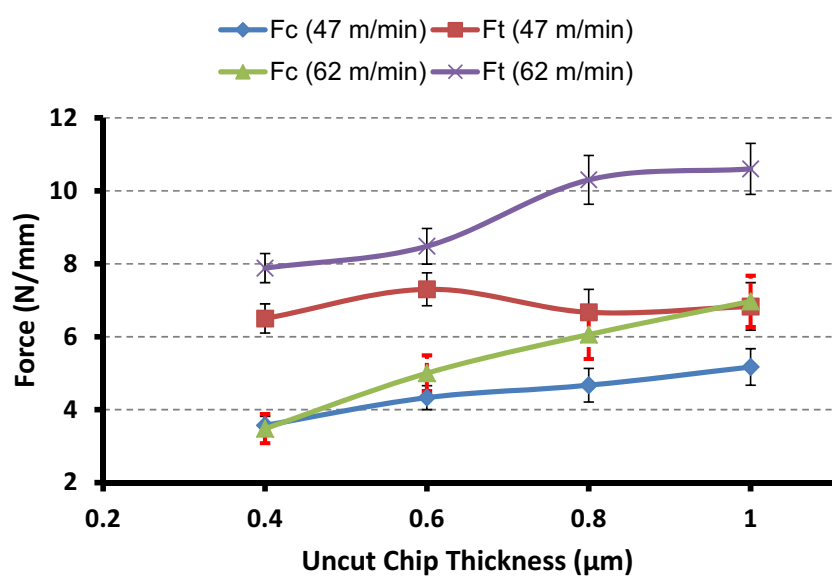

Fig. 2 Cutting $(\mathrm{Fc})$ and thrust (Ft) force measurement as a function of uncut chip thickness at cutting speed of $62 \mathrm{~m} / \mathrm{min}$ (width of cut $0.35 \mathrm{~mm}$ ) [17]

\section{Experimental analysis of microscale orthogonal machining}

Oliaei and Karpat [17] conducted microscale orthogonal cutting tests on titanium alloy Ti6Al4V and investigated the influence of BUE on process forces and surface. This section summarizes the experimental details of their work. The tungsten carbide micro cutting tools having a rake angle of $5^{\circ}$, clearance angle of $14^{\circ}$, and edge radius of $\sim 2 \mu \mathrm{m}$ were obtained through micro wire electric discharge machining process (WEDM). A micromachining center (Mikrotools DT110) was used to conduct microscale orthogonal cutting experiments. Titanium alloy hollow shafts with $10 \mathrm{~mm}$ diameter and $0.25-0.35 \mathrm{~mm}$ wall thickness were placed on the slow speed spindle (max $3000 \mathrm{rpm}$ ) for micro orthogonal cutting experiments. Micro cutting tools fabricated were attached to a tool holder which is mounted on Kistler mini dynamometer (9256). In orthogonal cutting experiments, the workpiece was fed towards the cutting tool with a certain feed rate based on required uncut chip thickness value. Uncut chip thickness values were selected to be smaller than the edge radius. The experiments were conducted for $12 \mathrm{~s}$. Their results showed a stable BUE at the tool tip, and it protects the cutting edge from crater wear under all experimental conditions tested. Figure 1a shows the SEM image of the cutting edge after machining where BUE formation on the cutting edge is clearly seen. Figure $1 \mathrm{~b}$ shows the $2 \mathrm{D}$ edge profiles of the tool tested at an uncut chip thickness of $1 \mu \mathrm{m}$. The edge radius of the BUE tip is measured to be around $4 \mu \mathrm{m}$. The rake angle in the presence of BUE is measured to be around $15-20^{\circ}$ using a laser microscope.

Figure 2 shows the force measurements as a function of cutting speed and uncut chip thickness. The presence of a built-up edge affects thrust forces more than cutting forces. A larger contact area due to BUE leads to greater forces. The cutting speed was shown to have an important influence on the cutting forces.

Experimental observations on machined surfaces also reveal that continuous chip formation ceases around $0.4 \mu \mathrm{m}$ of uncut chip thickness value, which is known as minimum uncut chip thickness [17]. The surface roughness measurements change as a function of speed, and they improve around $62 \mathrm{~m} /$ min cutting speed which corresponds to higher cutting and thrust forces. The average surface roughness (Rz) value was almost equal to uncut chip thickness just before continuous chip formation ceases [17].

\section{Analysis of stable built-up edge formation at microscale machining}

A 3D laser scanning microscope (VK-X110) has been used to investigate the geometry of the tools with the presence of built-up edge. Figure 3 illustrates a sample BUE measurement obtained at a cutting speed of $47 \mathrm{~m} / \mathrm{min}$ at an uncut chip thickness of $0.8 \mu \mathrm{m}$. It can clearly be seen that BUE formation significantly alters the edge radius, rake, and clearance angles of the cutting tool.

In order to analyze BUE formation as a function of process parameters, some features are defined as shown in Fig. 4. As a result of BUE, the effective tool rake angle which is usually negative during microscale machining becomes positive and the clearance angle decreases. As a result of low clearance angle and BUE length on the flank face, there is considerable contact between the workpiece and the cutting edge. The
Fig. 3 Built-up edge formation at $0.8 \mu \mathrm{m}$ uncut chip thickness
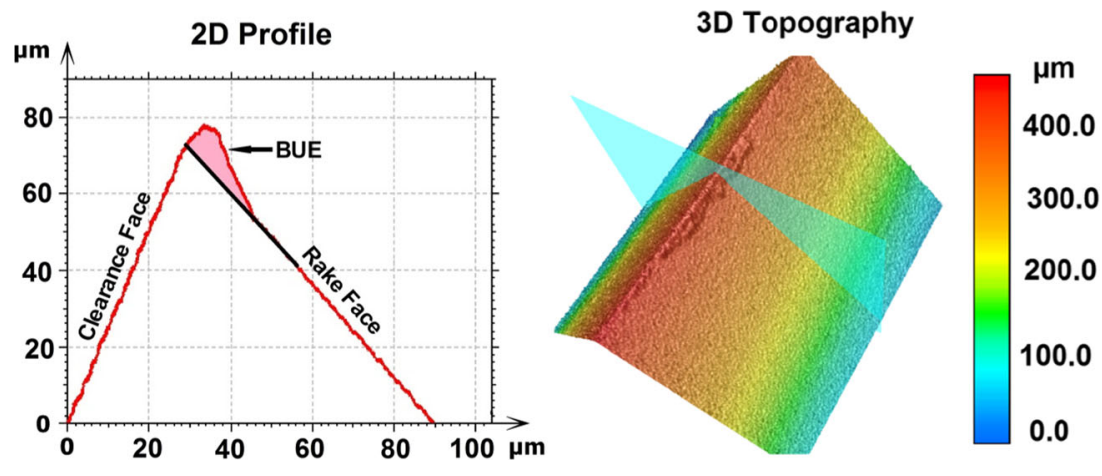
Fig. 4 Cutting tool parameters with the presence of stable BUE

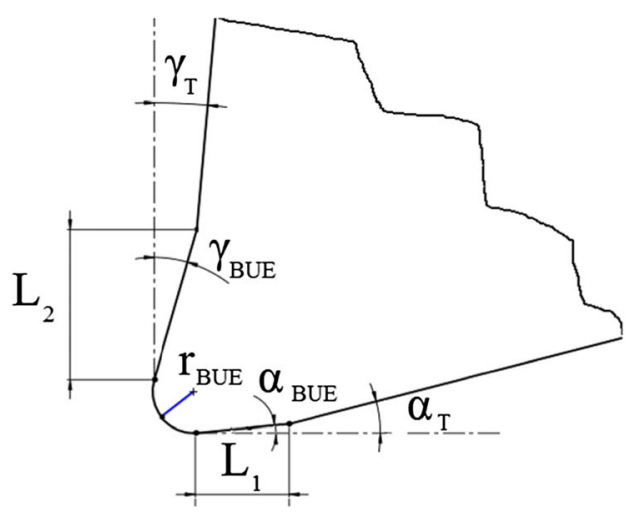

$\alpha_{\mathrm{T}}$ : Tool Clearance Angle

$\gamma_{\mathrm{T}}$ : Tool Rake Angle

$\alpha_{\text {BUE }}$ : BUE Clearance Angle

$\gamma_{\text {BUE }}:$ BUE Rake Angle

$r_{\text {BUE }}$ : BUE Edge Radius

$\mathrm{L}_{1}$ : BUE Length on Flank Face

$\mathrm{L}_{2}$ : BUE Length on Rake Face cutting edge radius of the BUE is measured to be similar to the edge radius of the cutting tool. The BUE parameters obtained for each experiment are shown in Table 1.

The length of BUE $\left(L_{1}\right.$ and $\left.L_{2}\right)$ increases with increasing uncut chip thickness $\left(t_{u}\right)$ based on the results given in Table 1 . Decreasing cutting speed leads to a smaller BUE formation with a smaller edge radius. Hartung and Kramer [14] observed a TiC layer, which prevents relative sliding at the tool chip interface and leads to a limited diffusion rate of the tool constituents to the work material. Supporting observations were made in [17] with slightly decreased amount of cobalt on the tool rake face.

\section{Finite element simulation model of microscale machining}

Finite element simulations are indispensible tools for machining research as they allow investigation of the relationship between machining conditions and process outputs. Material constitutive model and friction modeling are two main considerations in finite element modeling of machining.

Defining the friction condition at the tool-chip and the toolworkpiece interfaces is important, since it affects heat

Table 1 BUE parameters obtained under different machining conditions

\begin{tabular}{cllllll}
\hline $\begin{array}{l}\text { Cutting speed } \\
(\mathrm{m} / \mathrm{min})\end{array}$ & $\begin{array}{l}t_{u} \\
(\mu \mathrm{m})\end{array}$ & $\begin{array}{l}\alpha_{B U E} \\
(\text { Deg. })\end{array}$ & $\begin{array}{l}\gamma_{B U E} \\
(\text { Deg. })\end{array}$ & $\begin{array}{l}r_{B U E} \\
(\mu \mathrm{m})\end{array}$ & $\begin{array}{l}L_{1} \\
(\mu \mathrm{m})\end{array}$ & $\begin{array}{l}L_{2} \\
(\mu \mathrm{m})\end{array}$ \\
\hline \multirow{2}{*}{47} & 0.4 & 1 & 12 & 2.5 & 8 & 10 \\
& 0.6 & 1 & 15 & 2.5 & 10 & 16 \\
& 0.8 & 2 & 16 & 2 & 13 & 18 \\
& 1 & 2 & 15 & 2 & 14 & 22 \\
62 & 0.4 & 2 & 22 & 3 & 11 & 18 \\
& 0.6 & 3 & 18 & 3 & 13 & 20 \\
& 0.8 & 3 & 18 & 4 & 16 & 26 \\
& 1 & 3 & 20 & 4 & 19 & 35 \\
\hline
\end{tabular}

generation at the interfaces. Many different friction models have been proposed, and their influence on finite element simulations has been investigated in detail [26-28]. Two basic friction models are considered in this study. The first one relates the frictional stress $\left(\tau_{f}\right)$ at the tool-workpiece interface to normal stress $\left(\sigma_{n}\right)$ via Coulomb friction as:

$\tau_{f}=\mu \sigma_{n}$

The second one considers the relationship between friction $(\tau)$ at the tool-workpiece interface and the shear flow stress $(k)$ of the work material through shear friction factor $(m)$ as:

$\tau=m k$

In studies of finite element simulation of micromachining, a combination of these friction models are usually used. Thepsonti and Özel [29] considered sticking contact conditions $(m=0.9)$ around the edge radius and Coulomb friction on the rake face $(\mu=0.7$ for tungsten carbide and $\mu=0.4$ for $\mathrm{CBN}$ cutting tool material) while micromachining titanium alloy Ti6Al4V. Jin and Altintas [12] used sticking and sliding contact conditions during finite element modeling of micro milling where the Coulomb friction was taken as 0.15 for brass workpiece material. Afazov et al. [11] also assumed sticking and sliding conditions with coefficient friction of 0.4 for micro milling modeling of AISI 4340 steel. Thepsonti and Özel [30] used finite element simulation to model micro milling of titanium alloy Ti6Al4V. They considered sticking and sliding contact condition with Coulomb friction of 0.2 .

Table 2 The coefficients of the material model (Eq. (1)) [35]

\begin{tabular}{lllll}
\hline$a(\mathrm{MPa})$ & $n$ & $b(\mathrm{MPa})$ & $c$ & $\mathrm{D}$ \\
\hline 590 & 0.27 & 740 & $7.1903 \mathrm{e}-5$ & -0.0209 \\
$Q$ & $l$ & $p$ & $\varepsilon_{0}(1 / \mathrm{s})$ & $E$ \\
0.035 & 1.1 & 0.08 & 800 & 1.6356 \\
\hline
\end{tabular}


Fig. 5 Chip formation and velocity distribution in front of the cutting edge

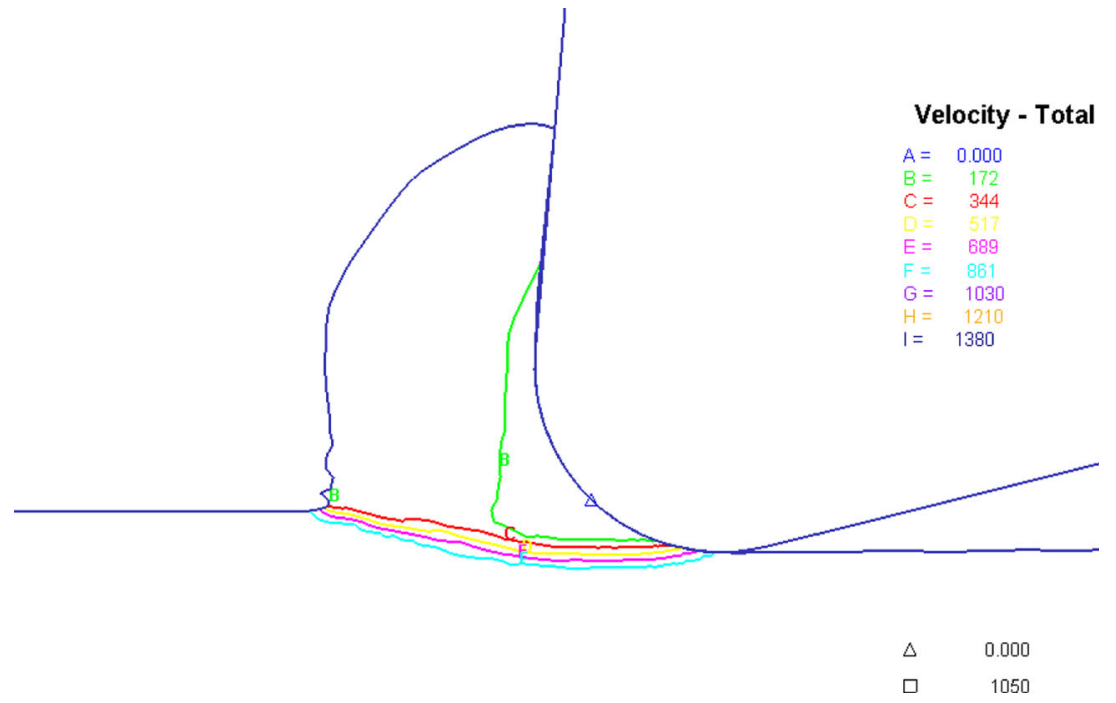

The material constitutive model employed in finite element simulation, together with friction definition, significantly affects the process output predictions. Many research papers have been published on this issue, mostly considering macroscale machining of titanium alloys ([31, 32]). In recent studies, material constitutive models have been improved to consider microstructural changes at high temperature machining conditions $([33,34])$.

In this study, a material model developed by Karpat [35] is adopted to simulate microscale machining of titanium alloy
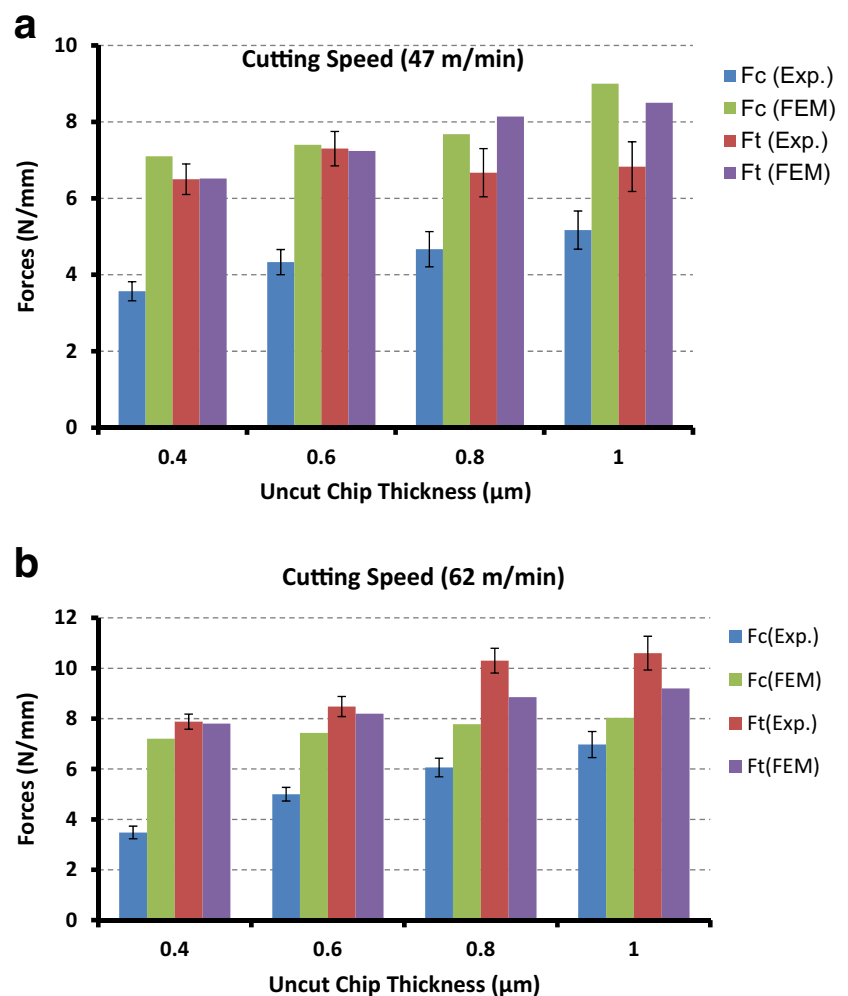

Fig. 6 Comparison of force measurement and predictions for friction factor of 0.95 at cutting speed of a $47 \mathrm{~m} / \mathrm{min}$ and b $62 \mathrm{~m} / \mathrm{min}$
Ti6AL4V. This material model was validated in a previous study for its ability to predict macroscale machining forces under various machining conditions. This material model considers strain softening as a function of temperature, and it was developed such that the influence of strain softening decreases as temperatures decrease. The model also considers the relationship between strain rate and strain. The material model is shown in Eq. 1 and the material model parameters are given in Table 2.

$\sigma(\varepsilon, \dot{\varepsilon}, T)=\left(a \varepsilon^{n}+b\right)\left(c T^{2}+d T+e\right) h(\varepsilon, \dot{\varepsilon})$
$h(\varepsilon, \dot{\varepsilon})=\left(1-\left[1-\left(\frac{\ln \left(\dot{\varepsilon}_{0}\right)}{\ln (\dot{\varepsilon})}\right)^{q}\right]\left[\frac{1}{l \times \tanh (\varepsilon+p)}\right]\right)$
$T=\frac{T}{T_{r}}$

A flow softening function, which initiates after a critical strain and temperature, was also integrated into Eq. (3) as shown in Eq. (4). The proposed function would control the softening behavior which occurs after a critical strain value. For strain values less than that critical strain, Eq. (3) is valid.

$\sigma_{\text {soft }}(\varepsilon, \dot{\varepsilon}, T)=\sigma-\left(\sigma-\sigma_{s}\right)\left(\tanh \left(k \varepsilon^{*}\right)^{r}\right)$

Mechanical and thermo-physical properties of titanium alloy Ti6Al4V are defined as a function of temperature $(T)$ : the Young's modulus $E(T)=-57.7 \times T+111,672(\mathrm{MPa})$, thermal expansion $\alpha(T)=3.10^{-9} \times T+7.10^{-6}\left(1 /{ }^{\circ} \mathrm{C}\right)$, thermal conductivity $\lambda(T)=0.015 \times T+7.7(\mathrm{~W} / \mathrm{m}$. K), and heat capacity $C_{p}(T)=2.7 \mathrm{e}^{0.0002 T}\left(\mathrm{~N} / \mathrm{mm}^{2} /{ }^{\circ} \mathrm{C}\right)[35]$. The heat transfer coefficient at the tool-chip interface is taken as a constant $5000 \mathrm{~W} /$ $\mathrm{m}^{2}{ }^{\circ} \mathrm{C}$. The workpiece is represented with 10,000 quadrilateral elements. The workpiece is modeled as elastic-plastic whereas the cutting edge is modeled as rigid. Simulations were run on commercial software DEFORM. 


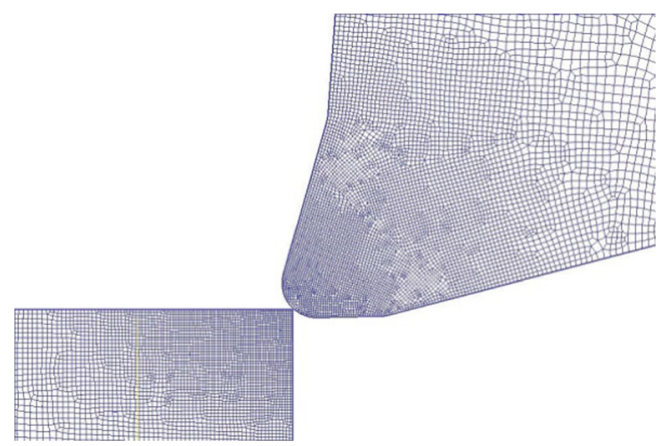

Fig. 7 Modified geometry of the cutting edge including BUE used in finite element simulations

In finite element simulation studies, a high friction factor $(\mathrm{m})$ is used to create sticking conditions at the tool chip interface which yields a low velocity region in front of the cutting edge is assumed to behave like a BUE [23, 25]. A high friction factor value of 0.95 was used in finite element simulations in order to examine the low-velocity region in front of the cutting edge and compare its dimensions with experimental measurements. Figure 5 shows the velocity distribution in front of the cutting edge together with the chip formation. The length of BUE on the flank face is about $5 \mu \mathrm{m}$ which is quite smaller than the experimental value of $19 \mu \mathrm{m}$.

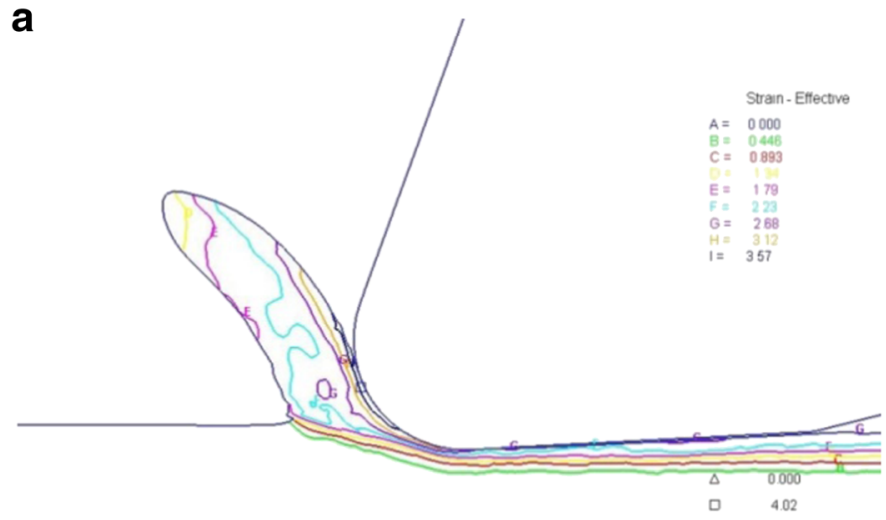

C

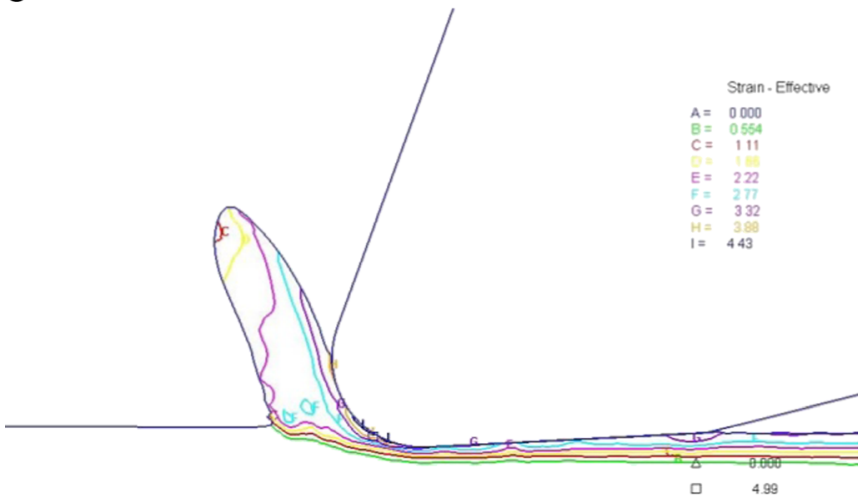

d

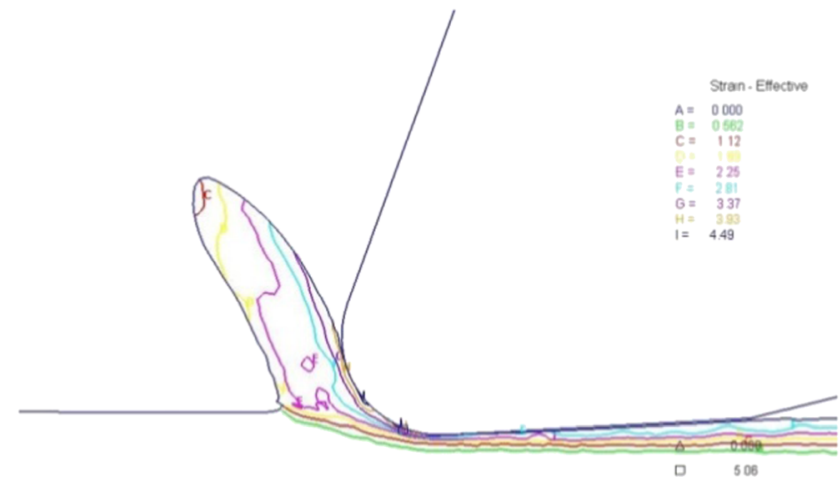

\section{Investigating the influence of friction models on finite element simulations}

In this study, an alternative approach has been used where the cutting edge geometry is modified based on experimental observations of BUE formation. For each simulation condition, the cutting edge geometry is modified based on values given in Table 1 . The modified geometry of the cutting edge with the presence of stable BUE is shown in Fig. 7.

Considering that BUE acts like a cutting edge, the contact conditions between BUE and the work material would be different. Budinski [36] investigated the tribological properties of titanium alloys and reported coefficient of friction

b

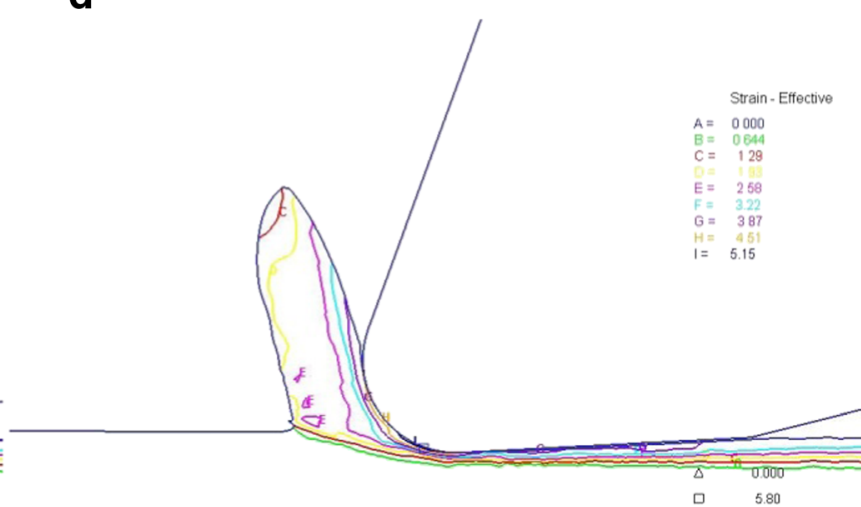

Fig. 8 Influence of coefficient of friction on the chip formation at uncut chip thickness of $1 \mu \mathrm{m}$ and cutting speed of $62 \mathrm{~m} / \mathrm{min}$ : Coulomb friction of a 0.1, b 0.2 , c 0.3 , and $\mathbf{d} 0.4$ 

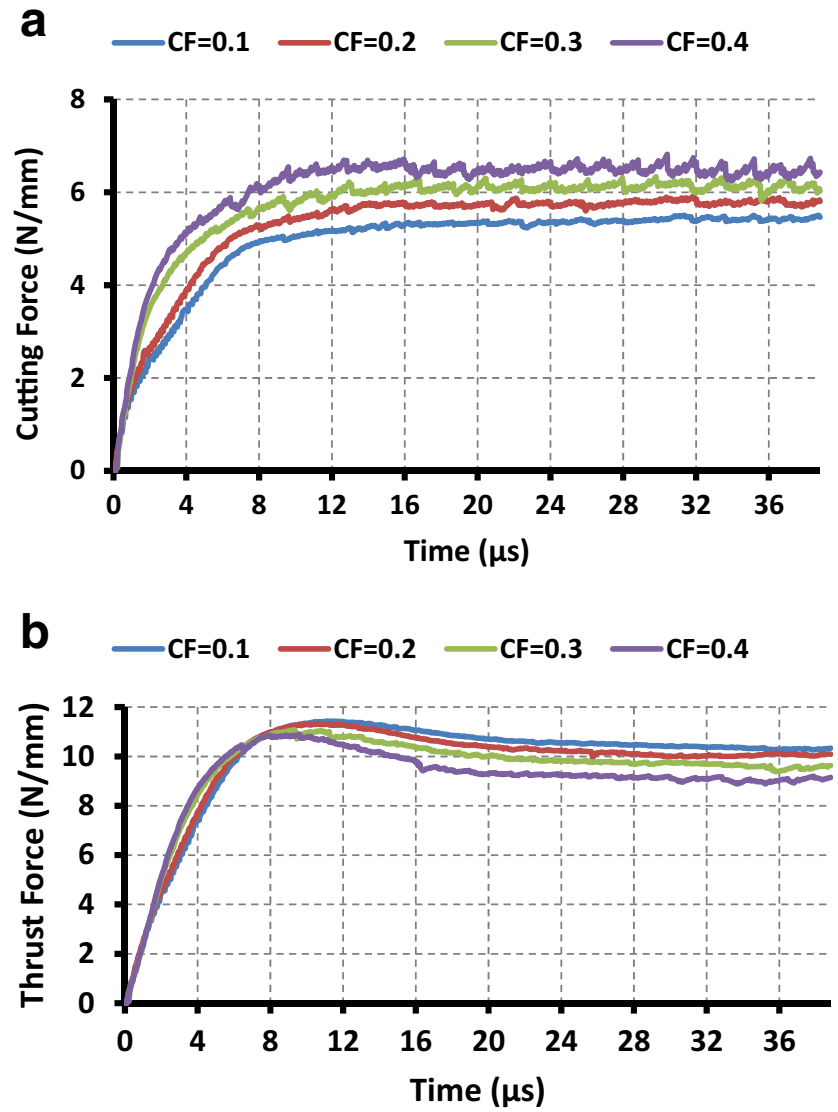

Fig. 9 Force predictions versus time obtained from finite element simulation model for uncut chip thickness of $1 \mu \mathrm{m}$ at $62 \mathrm{~m} / \mathrm{min}$ at various Coulomb friction conditions. a Cutting force predictions. b Thrust force predictions

between Ti6Al4V pair as 0.31. Zhang and Tanaka [37] used molecular dynamics approach to study wear and friction for low uncut chip thickness values. They concluded that Coulomb friction rule is valid during micro cutting regime and lower coefficient of friction values were calculated as a function of indentation depth during adhering stage. Venkatachalam and Liang [38] also studied the variation of coefficient of friction during microscale machining and stated that for low values of indentation, the coefficient of friction depends on the adhering effect. In this study, the material constitutive model was kept constant and friction models were investigated.

\subsection{Finite element simulations with Coulomb friction model}

The influence of the coefficient of friction on the finite element simulation outputs is first investigated under Coulomb friction assumption between the BUE and the work material. Four different friction conditions are considered: Coulomb friction of $0.1,0.2,0.3$, and 0.4 based on the findings of Budinski [36] and Zhang and Tanaka [37]. Figure 8 shows the chip formation for $1 \mu \mathrm{m}$ uncut chip thickness under four
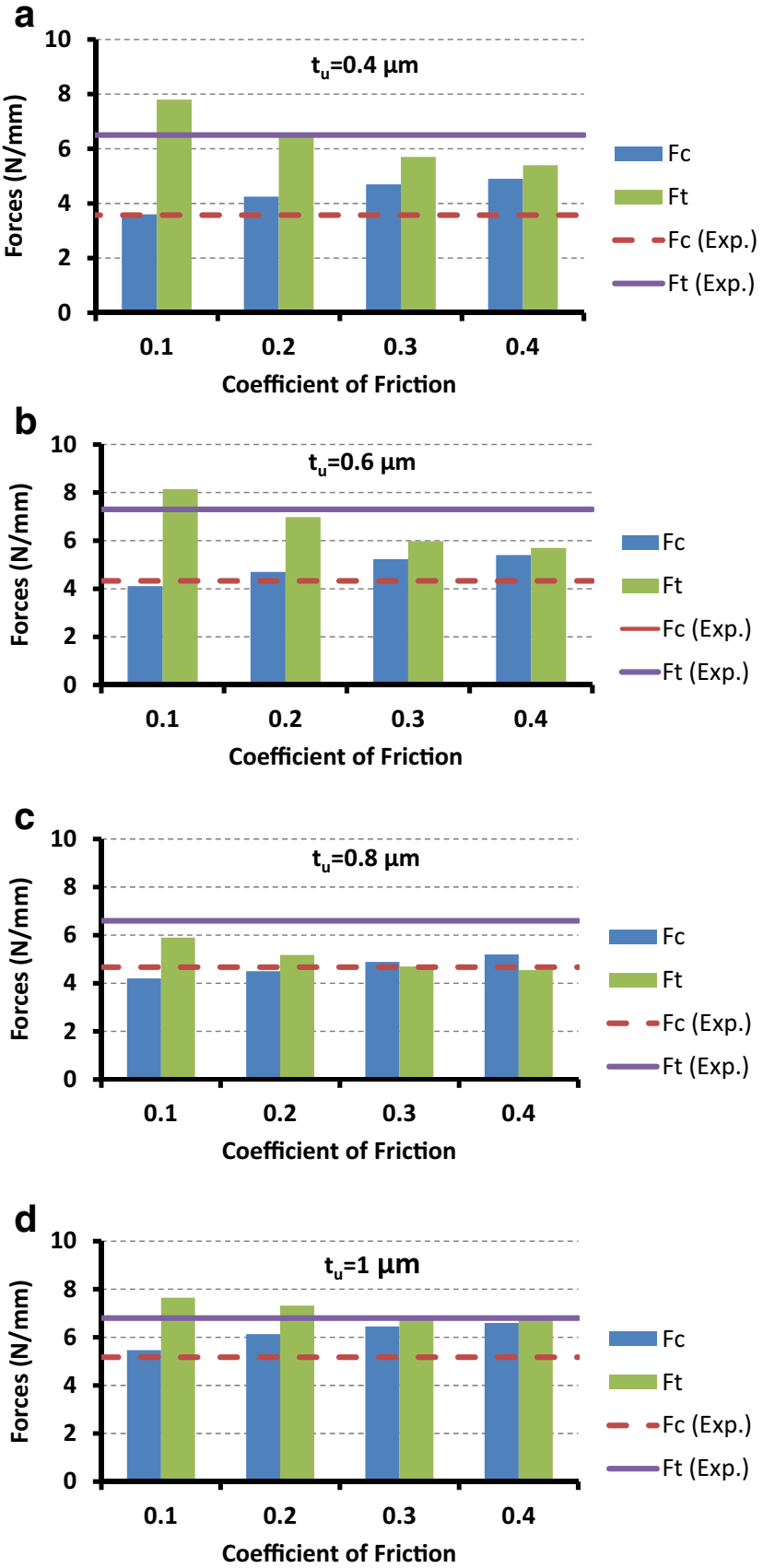

Fig. 10 Force predictions as a function of coefficient of friction for uncut chip thickness of a 0.4 , b $0.6, \mathbf{c} 0.8$, and $\mathbf{d} 1 \mu \mathrm{m}$ at $47 \mathrm{~m} / \mathrm{min}$

different friction conditions. As coefficient of friction increases, calculated strain on the machined surface also increases in the simulations. The coefficient of friction affects the thickness and shape of the chip. Increasing coefficient friction decreases chip curvature. Considering the fact that the cutting edge is actually the BUE, one may expect to observe contact between the chip and the BUE along the rake face. With Coulomb friction model, however, finite element simulation did not yield such chip shapes. Since micromachining requires small uncut chip thickness values, 
it is a challenge to measure the cut chip thicknesses. No reliable measurement of cut chip thickness was possible in the experiments. Therefore, no chip thickness comparison can be made.

Figure 9 shows the variation of cutting and thrust forces with time for different coefficient of friction values. The cutting $\left(F_{c}\right)$ and thrust $\left(F_{t}\right)$ forces reach a steady state value after microchip is formed. The thrust forces are simulated to be larger than cutting forces, which agrees with the experiments. Figure 10 shows the influence of coefficient of friction on simulated cutting and thrust forces in comparison to experimental forces. Increasing coefficient of friction increases cutting force and decreases thrust force. Based on the simulation results, coefficient of friction of 0.2 yielded better predictions for uncut chip thickness values of 0.4 and $0.6 \mu \mathrm{m}$, whereas coefficient of friction of 0.1 yielded better predictions for uncut chip thickness values of 0.8 and $1 \mu \mathrm{m}$.

Figure 11 summarizes the force predictions at 47 and $62 \mathrm{~m} /$ min cutting speed under Coulomb friction model assumption. In the simulations for the cutting speed of $62 \mathrm{~m} / \mathrm{min}$, a coefficient of friction of 0.3 resulted in best predictions. Force predictions at $47 \mathrm{~m} / \mathrm{min}$ matches experimental results better compared to $62 \mathrm{~m} / \mathrm{min}$ considering the upper and lower experimental limits. Increasing cutting speed results in higher
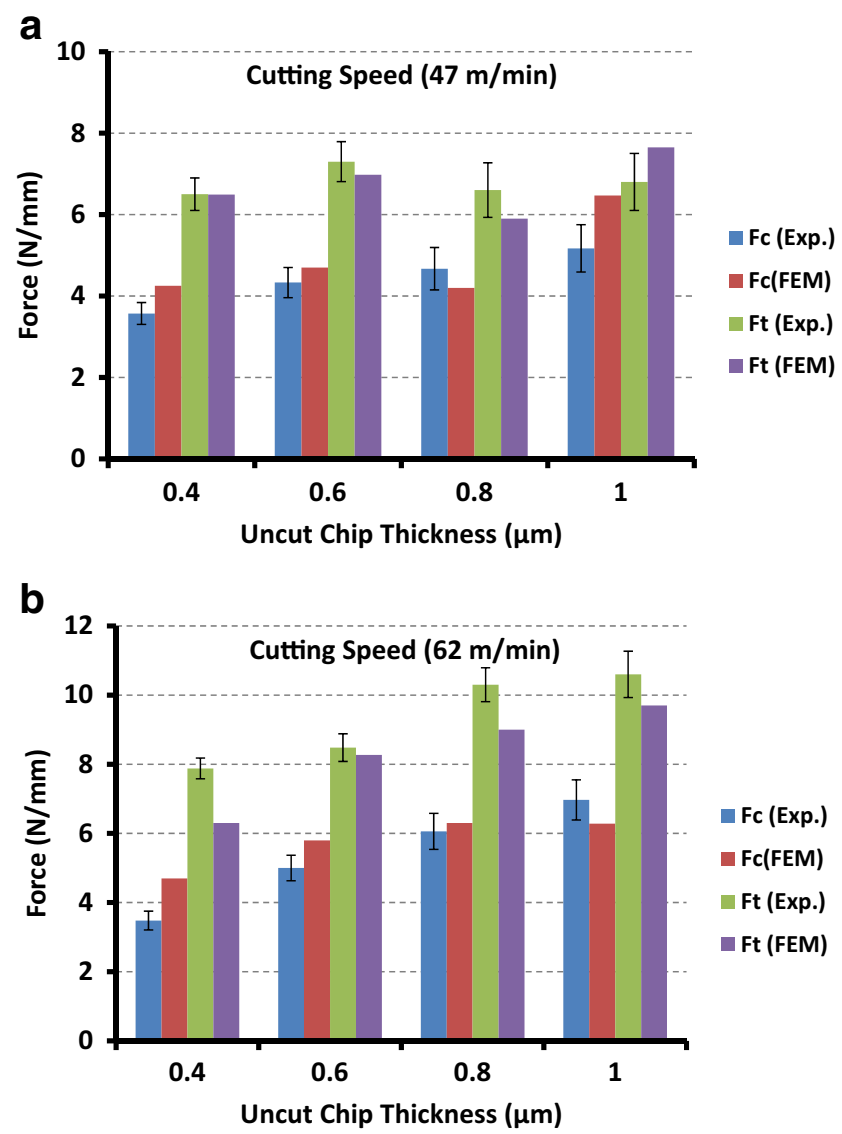

Fig. 11 Force predictions for different uncut chip thickness values for: a cutting speed of $47 \mathrm{~m} / \mathrm{min}$, b cutting speed of $62 \mathrm{~m} / \mathrm{min}$ temperatures at the cutting zone, where the adhesion of the cut material to the BUE becomes easier. Increasing BUE size develops larger cutting forces. Coulomb friction with equivalent edge assumption yielded significantly better force predictions compared to high friction factor with original cutting edge. However, the chip shape with low coefficient of friction values was not in agreement with experimental observations.

\subsection{Finite element simulation with hybrid friction conditions}

In hybrid friction model, a friction window approach has been used in which sticking conditions $(m)$ are assumed on the rake face and sliding friction $(\mu)$ conditions are assumed on the flank face of the cutting tool. A large friction factor on the rake face yields larger chips, which remain in contact with the rake face of the tool. Figure 12 shows the hybrid friction model used in this study. Different combinations of Coulomb friction $(\mu)$ and shear friction $(m)$ values are considered. Shear friction is varied between 0.7 and 0.95 and Coulomb friction is varied between 0.1 and 0.3 . Table 3 shows the combinations used in the simulations where a total of nine cases are considered.

Figure 13 illustrates the influence of hybrid friction definition on the chip formation at uncut chip thickness of $1 \mu \mathrm{m}$ and cutting speed of $62 \mathrm{~m} / \mathrm{min}$. Compared to Fig. 8, chip shape formation is changed and the chip flows on the rake face formed by the BUE. As a result of using an elastic-plastic finite element model, the contact at the BUE-work surface interface also matches the experimental observations. Figure 14 illustrates the finite element force predictions at different combinations of Coulomb friction and shear factor for uncut chip thickness of $1 \mu \mathrm{m}$ at a cutting speed of $62 \mathrm{~m} / \mathrm{min}$. A Coulomb friction of 0.2 and shear factor of 0.8 resulted in the closest predictions compared to experimental results. The influence of friction conditions on the forces seem to be low.

Figure 15 illustrates finite element predictions and experimental machining forces at two different cutting

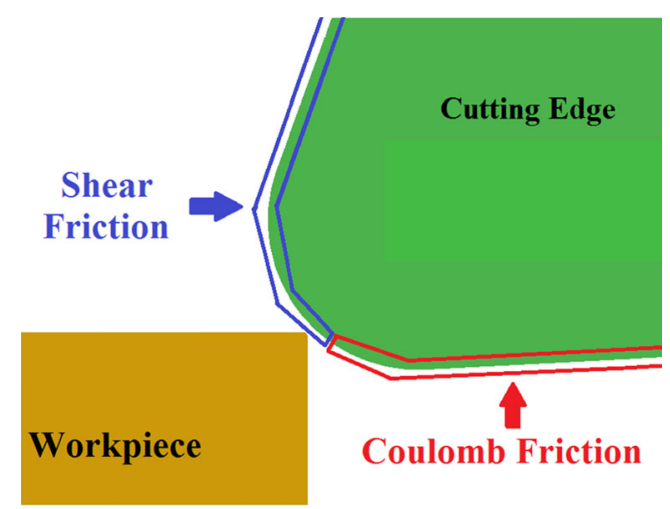

Fig. 12 Hybrid friction model used in the finite element simulation with the presence of BUE 
Table 3 Friction definitions in the hybrid model

\begin{tabular}{llllllllll}
\hline Model & 1 & 2 & 3 & 4 & 5 & 6 & 7 & 8 & 9 \\
\hline Friction definitions & $\mu=0.1$ & $\mu=0.1$ & $\mu=0.1$ & $\mu=0.2$ & $\mu=0.2$ & $\mu=0.2$ & $\mu=0.3$ & $\mu=0.3$ & $\mu=0.3$ \\
& $m=0.7$ & $m=0.8$ & $m=0.95$ & $m=0.7$ & $m=0.8$ & $m=0.95$ & $m=0.7$ & $m=0.8$ & $m=0.95$
\end{tabular}

speeds using the hybrid friction model. The same friction coefficients identified for $62 \mathrm{~m} / \mathrm{min}$ cutting speed and
$1 \mu \mathrm{m}$ uncut chip thickness were used in all simulations and acceptable results were obtained except $0.4 \mu \mathrm{m}$ uncut

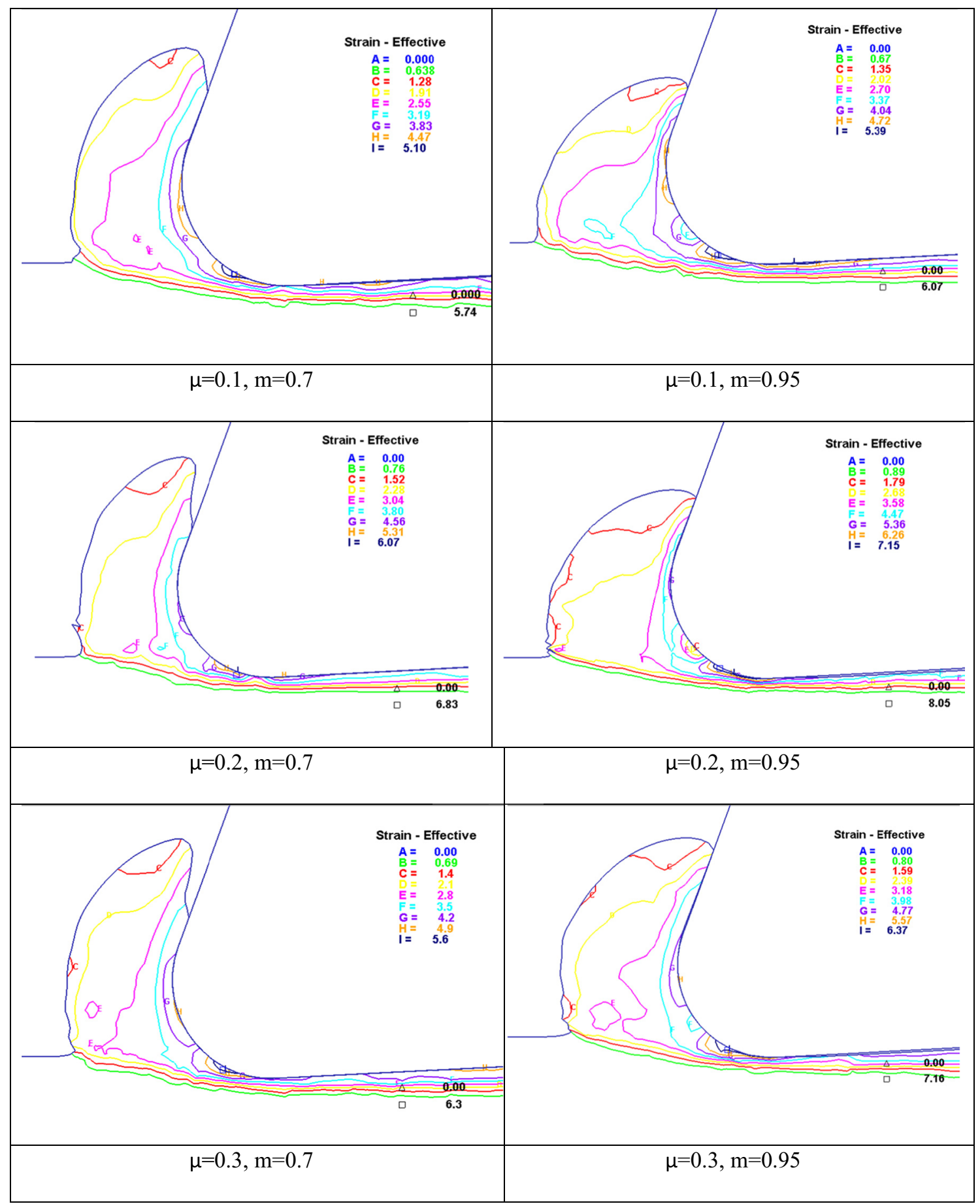

Fig. 13 Finite element simulations of chips for hybrid friction model 


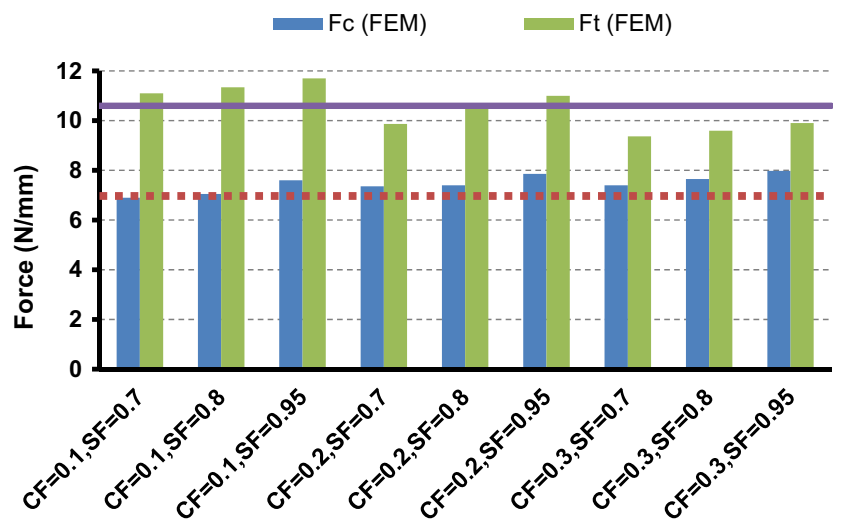

Fig. 14 Finite element predictions at different $\mu$ and $m$ values for an uncut chip thickness of $1 \mu \mathrm{m}$ at cutting speed of $62 \mathrm{~m} / \mathrm{min}$

chip thickness. It must be noted that a better fit would be obtained in predictions for each machining case by fine tuning friction coefficients. Considering process variability in micromachining, these were not calculated. As for uncut chip thickness of $0.4 \mu \mathrm{m}$, while the thrust force predictions are acceptable, the cutting force predictions did not match well with the measurements. Cutting force predictions are known to be related to cut chip thickness, and uncut chip thickness of $0.4 \mu \mathrm{m}$ was found to be the minimum uncut chip thickness. Therefore, it is quite
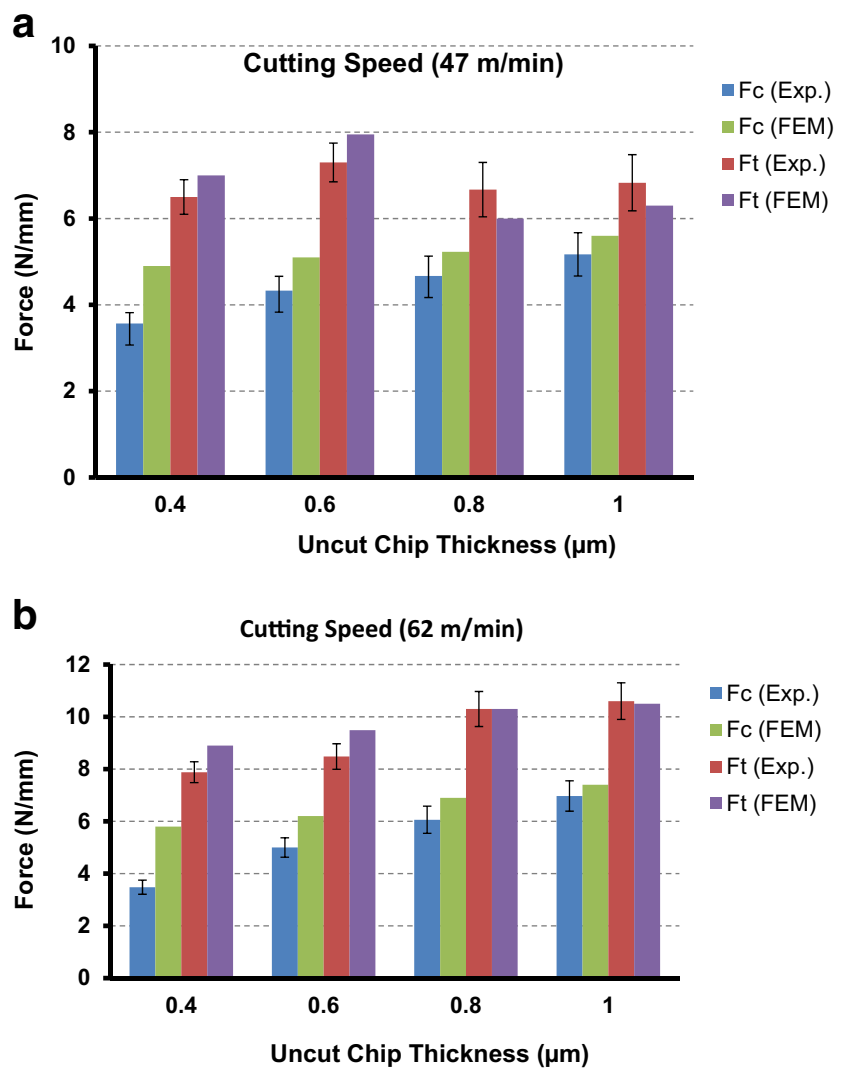

Fig. 15 Comparison of force measurement and predictions for hybrid friction conditions Coulomb friction of 0.2 and shear factor of 0.8 at cutting speed of a $47 \mathrm{~m} / \mathrm{min}, \mathbf{b} 62 \mathrm{~m} / \mathrm{min}$ likely that the mechanics of cutting and contact conditions are different here than in other machining cases.

The results of this section indicate that the hybrid friction modeling technique, together with a modified tool edge geometry approach, yields acceptable results when the cutting edge is modified with actual BUE dimensions. It must be noted that the material constitutive model and friction definitions are closely related. Using a different material model in finite element simulations would yield a different set of friction coefficients.

\section{Conclusions}

This study investigated a finite element simulation model for microscale machining of titanium alloy. Built-up edge formation has been included in the simulation by modifying the cutting edge geometry based on experimental observations. The influence of friction conditions on finite element simulations has been investigated based on basic friction models. It is found that:

- Proposed finite element model is successful at predicting machining forces and chip shapes.

- Using high friction factor to simulate BUE was observed to be insufficient in finite element simulations of micromachining. Using a different material model would yield different results. However, considering the differences in simulated low velocity region and measured BUE size, it does not seem reasonable.

- The results reveal the importance of predicting the size and shape of built-up edge formation during micromachining.

- A hybrid friction model where the rake face is modeled with shear friction factor of 0.8 and flank face is modeled with Coulomb friction of 0.2 yielded acceptable results for all machining cases where continuous chip forms.

- Finite element simulation predictions improve as uncut chip thickness increases. Finite element simulation predictions at uncut chip thickness of $0.4 \mu \mathrm{m}$ significantly deviate from measurements in terms of cutting force which was observed to be the limit of transition from continuous to discontinuous chip formation.

- The finite element simulation model with identified friction conditions can be employed within mechanistic machining models to predict micro milling process forces.

Acknowledgments The authors would like to thank The Scientific and Technological Research Council of Turkey (TÜBITAK-110M660, National Young Researcher Career Development Program) and State Planning Organization of Turkey (HAMIT-Micro System Design and Manufacturing Research Center). 


\section{References}

1. Nano and micromachining, J. Paulo Davim (Editor), Mark J. Jackson (Editor) ISBN: 978-1-84821-103-2, December 2008, Wiley-ISTE

2. Câmara MA, Campos Rubio JC, Abrão AM, Davim JP (2012) State of the art on micromilling of materials, a review. Journal of Materials Science \& Technology 28(8):673-685

3. Cardoso P, Davim JP (2012) A brief review on micromachining of materials. RevAdv Mater Sci 30:98-102

4. Lucca DA, Seo YW (1993) Effect of tool edge geometry on energy dissipation in ultraprecision machining. Ann CIRP 42(1):83-86

5. Lamikiz A, López de Lacalle LN, Sanchez JA, Bravo U (2005) Calculation of the specific cutting coefficients and geometrical aspects in sculptured surface machining. Mach Sci Technol 9(3):411436. doi:10.1080/15321790500226614

6. Uriarte L, Azcárate S, Herrero A, Lopez de Lacalle LN, Lamikiz A (2008) Mechanistic modelling of the micro end milling operation. Proc Inst Mech Eng B J Eng Manuf 222:23-33

7. Zhang X, Ehmann KF, Yu T, Wang W (2016) Cutting forces in micro-end-milling processes. Int J Mach Tools Manuf 107:21-40

8. Srinivasa YV, Shunmugam MS (2013) Mechanistic model for prediction of cutting forces in micro end-milling and experimental comparison. International Journal of Machine Tools Manufacture 67:18-27

9. Malekian M, Park SS, Jun MBG (2009) Modeling of dynamic micro-milling cutting forces. International Journal of Machine Tools Manufacture 49:586-598

10. Gonzalo O, Jauregi H, Uriarte LG, López de Lacalle LN (2009) Prediction of specific force coefficients from a FEM cutting model. Int J Adv Manuf Technol 43:348. doi:10.1007/s00170-008-1717-9

11. Afazov SM, Ratchev SM, Segal J (2010) Modelling and simulation of micro-milling cutting forces. J Mater Process Technol 210:2154-2162

12. Jin X, Altintas Y (2012) Prediction of micro-milling forces with finite element method. J Mater Process Technol 212:542-552

13. Lazoglu I, Mamedov A (2016) Deformation of thin parts in micromilling. CIRP Ann Manuf Technol 65:117-120

14. Hartung PD, Kramer BM (1982) Tool wear in titanium machining. Annals of CIRP 32:75-80

15. Kümmel J, Gibmeier J, Müller E, Schneider R, Schulze V, Wanner A (2014) Detailed analysis of microstructure of intentionally formed built-up edges for improving wear behaviour in dry metal cutting process of steel. Wear 311:21-30

16. Kümmel J, Braun D, Gibmeier J, Schneider J, Greiner C, Schulze V, Wanner A (2015) Study on micro texturing of uncoated cemented carbide cutting tools for wear improvement and built-up edge stabilisation. J Mater Process Technol 215:62-70

17. Oliaei SNB, Karpat Y (2016) Investigating the influence of built-up edge on forces and surface roughness in micro scale orthogonal machining of titanium alloyTi6Al4V. J Mater Process Technol 235:28-40

18. Gomez-Parra A, Alvarez-Alcon M, Salguero J, Batista M, Marcos M (2013) Analysis of the evolution of the built-up edge and built-up layer formation mechanisms in the dry turning of aeronautical aluminium alloys. Wear 302:1209-1218

19. Desaigues JE, Lescalier C, Bomont-Arzur A, Dudzinski D, Bomont O (2016) Experimental study of built-up layer formation during machining of high strength free-cutting steel. J Mater Process Technol 236:204-215
20. Waldorf DJ, DeVor RE, Kapoor SG (1999) An evaluation of ploughing models for orthogonal machining. J Manuf Sci Eng 121:550-558

21. Fang N, Dewhurst P (2005) Slip-line modeling of built-up edge formation in machining. Int J Mech Sci 47:1079-1098

22. Karpat Y (2009) Investigation of the effect of cutting tool edge radius on material separation due to ductile fracture in machining. Int J Mech Sci 51(7):541-546

23. Kim J, Marinov VR, Kim D (1997) Built up edge analysis of orthogonal cutting by the visco plastic finite element method. J Mater Process Technol 71:367-372

24. Childs THC (2013) Ductile shear failure damage modelling and predicting built-up edge in steel machining. J Mater Process Technol 213:1954-1969

25. Atlati S, Haddag B, Nouari M, Moufki A (2015) Effect of the local friction and contact nature on the built-up edge formation process in machining ductile metals. Tribol Int 90:217-227

26. Özel T (2006) The influence of friction models on finite element simulations of machining. Int J Mach Tools Manuf 46(5):518-530

27. Arrazola PJ, Ugarte D, Domínguez X (2012) A new approach for the friction identification during machining through the use of finite element modeling. Int J Mach Tools Manuf 48(2):173-183

28. Arrazola PJ, Özel T, Umbrello D, Davies M, Jawahir IS (2013) Recent advances in modelling of metal machining processes. CIRP Ann Manuf Technol 62:695-718

29. Thepsonthi T, Özel T (2013) Experimental and finite element simulation based investigations on micro-milling Ti-6Al-4V titanium alloy: effects of cBN coating on tool wear. J Mater Process Technol 213:532-542

30. Thepsonthi T, Özel T (2015) 3-D finite element process simulation of micro-end milling Ti-6Al-4V titanium alloy: experimental validations on chip flow and tool wear. J Mater Process Technol 221: 128-145

31. Calamaz M, Coupard D, Girot F (2008) A new material model for 2D numerical simulation of serrated chip formation when machining titanium alloy Ti-6Al-4V. Int J Mach Tools Manuf 48:275-288

32. Sima M, Özel T (2010) Modified material constitutive models for serrated chip formation simulations and experimental validation in machining of titanium alloy Ti-6Al-4V. Int J Mach Tools Manuf 50:943-960

33. Liu R, Melkote S, Pucha R, Morehouse J, Man X, Marusich T (2013) An enhanced constitutive material model for machining of Ti-6Al-4V alloy. J Mater Process Technol 213:2238-2246

34. Zhang XP, Shivpuri R, Srivastava AK (2014) Role of phase transformation in chip segmentation during high speed machining of dual phase titanium alloys. J Mater Process Technol 214:30483066

35. Karpat Y (2011) Temperature dependent flow softening of titanium alloy Ti6Al4V: an investigation using finite element simulation of machining. J Mater Process Technol 211:737-749

36. Budinski KG (1991) Tribological properties of titanium alloys. Wear 151:203-217

37. Zhang L, Tanaka H (1997) Towards a deeper understanding of wear and friction on the atomic scale: a molecular dynamics analysis. Wear 211:44-53

38. Venkatachalam S, Liang SY (2007) Effects of ploughing forces and friction coefficient in microscale machining. J Manuf Sci Eng 129: 274-280 